\title{
Synthesis of some 2-Aryl -1,3,4-Thiadiazoline-2-One Derivatives
}

\author{
Salim J. Mohammad \\ Department of Chemistry \\ College of Science \\ Mosul University
}

(Received 20/12/2010;Accepted 4/4/2011)

\begin{abstract}
To synthesis of some new heterocyclic compounds containing 1,3,4-thiadiazole moieties. Many of 5-alkyl-3-(4-substituted-2-butyn-1-yl) -1,3,4-thiadaizoline-2(3H)-one (15a-e and 16a-e) have been prepared by the reactions sequences starting from the acid hydrazides (1 and 2). All the products are well known for their useful biological activities. The structures of all compounds were confirmed by physical and spectral methods.
\end{abstract}

Keywords: 1,3,4-thiadiazole-2-one, Manich reaction.

\section{تحضير بهض ششقل 2 - الرل - 4,3,1 - شليادليازولين -2 - لهن}

\section{الملغص}

مُ تحضير بعض المركبت الحلقي ـة غير المتجلنس ـة الحاوية على حلق ـة 4,3,1 - ثايادالي ـ ازازول ،

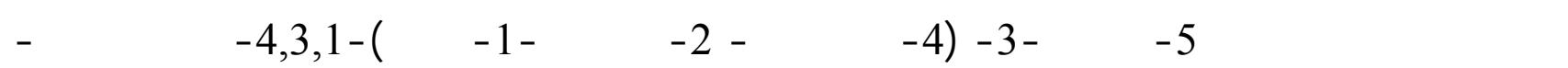

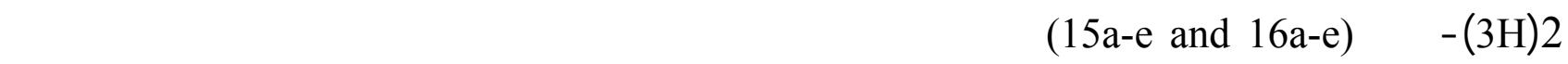

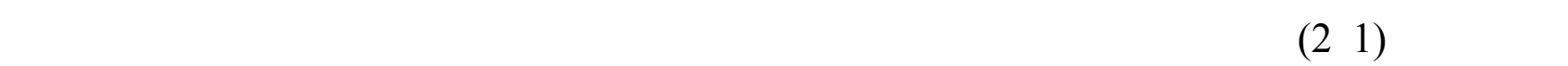
التركيبية للمركبلت المحضرة من خلال لستخدلم الطرائق الفيزيائية والطيفية المتوفرة.

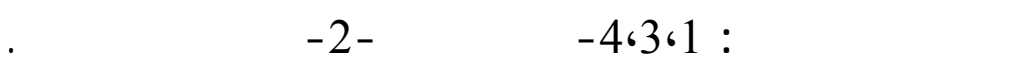

\section{INTRODUCTION}

Numerous 1,3,4- thiadiazole derivatives are classes of heterocycles, which have a wide range of biological activities in medicinal chemistry including potential antimicrobial agent (Aly and Alsyed, 2006), (Vosooghi et al., 2005), antibacterial (Dobholkar et al., 2009), anticonvulsant and muscle relaxant ( Siddiqui et al., 2009), (Almasirad et al., 2007), also such these compounds exhibited significant inhibitory activity agent (Mohammad et al., 2009), others such compounds have fungicidal activity (Chen et al., 1999) and as antiamebic agent (Singh and Longer, 1989). 
Acetylenic compounds were found to be high significant in medical science, since the medical compounds of acetylenic system have a higher activity and lower toxicity (AL-Ajely et al., 2003). Some of the acetylenic derivatives showed both oxetermrine and acetylcholine antagonistic activity (Zuhair Muhi-Elden et al., 1981). Several acetylenic amines showed anticholinergic activity and ability to inhibit tremors (Dahlbom and Mollberg, 1963).

In view of these observations, it was thought to synthesize some 5-alkyl-3-(4substituted-2-butyn-1-yl)-1,3,4-thiadiazole-2(3H)-ones (15a-e) and (16a-e) have been expected to posses an antagonistic activity towards acetylcholine and oxotremorine (Zuhair Muhi- Elden et al., 1985).

Accordingly, we describe here an approach to synthesize some acetylene compounds containing 1,3,4 thiadiazole moiety as depicted in (scheme 1) to improve the expected biological activities of such compounds.

\section{EXPERIMENTAL}

Melting points were determined using electro thermal 9300 melting point apparatus and are uncorrected. IR Spectra were recorded by Bruker 96565 Spectroscopy as (KBr disk). UV Spectra were recorded on Shimadzu (UV-1600) UV-Visible Spectrophotometer using methanol as a solvent. All the starting material were used either from Fluka or Aldrich chemical products. The secondary amines were use with further purification. The acid hydrazides (1 and 2) were prepared as previously described by (EL-Khwass, 1989). (Noori, 1999), m.p. (173-174 ${ }^{\circ} \mathrm{C}$ ) (Adams and 141-143 ${ }^{0} \mathrm{C}$ ). (Noori, 1999) respectively .

\section{Preparation of potassium-3-substituted methyl dithiocarbazates (3 and 4) (Hoggarth,} 1952 ).

To a mixture of acid hydrazide (1and 2) (0.01 mole) in absolute ethanol $(50 \mathrm{ml})$ containing potassium hydroxide $(0.015$ mole, 0.84 gm $)$ carbon disulfide $(0.015$ mole, $1.71 \mathrm{gm})$ was added, then the reaction mixture stirred at room temperature for (24 hours). Yellow precipitate of the corresponding compounds was separated, dry ether $(100 \mathrm{ml})$ was added to complete the precipitation of the formed salts. The products was filtered off, washed with dry ether and crystallized from aqueous ethanol. Physical data of compounds (3and 4) are listed in Table (1).

\section{Preparation of methyl-3-substituted methyl dithiocarbazates(5and 6) (Noori, 1999):}

Methyl iodide $(0.01$ mole, $0.15 \mathrm{gm})$ was added to a stirred solution of compounds (3and 4) ( 0.009 mole) in $(50 \mathrm{ml})$ of water for two hours. The white solid was filtered washed with water and crystallized from aqueous methanol to give the corresponding products (5 and 6) as a pale yellow crystals. Physical data of these products are listed in Table (1).

\section{Preparation of 5-alkyl -2-methylthio-1,3,4-thiadiazoles (7 and 8) (Noori, 1999):}

Methyl dithiocarbazates ( 5 and 6) was dissolved in a minimum amount of concentrated sulfuric acid $(3 \mathrm{ml})$ at room temperature, the mixture was poured on ice. The pale-yellow precipitate was filtered off and crystallized from aqueous methanol to give the products (7 and 8). Physical data of the two products are shown in Table (1). 
Preparation of 5-alkyl-2-methylsulfonyl-1,3,4-thiadiazole (9 and 10)(Ludwig et al., 1973):

The 5- alkyl-2 - methylthio -1,3,4-thiadiazoles (7 and 8) (0.05 mole) was dissolved in glacial acetic acid $(10 \mathrm{ml})$, potassium permanganate $(1.58 \mathrm{gm}, 3 \%)$ was added and the mixture was stirred at $\left(40 \mathrm{C}^{\circ}\right)$ for three hours. The reaction mixture was decolorized with sodium hydrogen sulphite at $\left(0 \mathrm{C}^{\circ}\right)$. The crude solid product was collected and crystallized from aqueous ethanol to give the products (9 and 10$)$. The physical data of these products are listed in Table (1).

\section{Preparation of 5-alkyl-1,3,4-thiadiazoline-2(3H)-one (11 and 12) (Zuhair Muhi-Elden} et al., 1985):

5-alkyl-2-methylsulfonyl-1,3,4-thiadiazoles (9 and 10) (0.005 mole) was added to $(10 \mathrm{ml})$ aqueous sodium hydroxide solution. The mixture was refluxed for a half hour , and the product was acidified with diluted acetic acid. The crude solid product was collected and recrystallized from aqueous methanol to give pure products (11 and 12). Physical data for compounds (11 and 12) are listed in Table (1).

Preparation of 5-alkyl-3-proporgyl-1,3,4-thiadiazoline-2(3H)-ones (13 and 14) (Zuhair Muhi-Elden et al., 1985):

To a solution of ( 0.005 mole $)$ of 5 -alkyl-1,3,4-thiadiazoline-2(3H)-ones (11 and 12) in $(30 \mathrm{ml})$ of ethanol, $(0.01 \mathrm{~mole})$ of potassium hydroxide was added slowly, the stirred solution was refluxed for (15 minutes) and $(0.11$ mole, $13.1 \mathrm{gm})$ of propargylbromide was added drop-wise. The stirred mixture was refluxed for an additional ( 2 hours). After cooling , $250 \mathrm{ml}$ of water was added, the crude solid products was collected and crystallized from methanol. Physical data for compounds (13 and 14) are listed in Table (1).

\section{Preparation of 5-alkyl-3-(4-substituted-2-butyn-1-yl)-1,3,4-thiadiazoline-2(3H)-one (15a-e and 16a-e) (Zuhair Muhi-Elden et al., 1985):}

Appropriate secondary amine $(0.003$ mole) was added to a mixture of 5-alkyl-3proporgyl -1,3,4-thiadiazoline-2(3H)-one (13 and 14) $(0.003 \mathrm{~mol})$, paraformaldehyde $(0.003$ mole) and catalytic amount of cuprous chloride in $(10 \mathrm{ml})$ hydrogen peroxide $(30 \%)$, the mixture was heated at $(70-80) c^{\circ}$ for $(3$ hours) with continuous stirring. The products (15a-e and 16a-e) was filtered and recrystallized from aqueous methanol. The physical data for these products are shown Table (2). 
Table 1: Physical data of compounds(3-14).

\begin{tabular}{|c|c|c|}
\hline $\begin{array}{c}\text { Compd. } \\
\text { No. }\end{array}$ & $\begin{array}{c}\text { M.P. } \\
\mathbf{C}^{\circ}\end{array}$ & $\begin{array}{c}\text { Yield } \\
\text { \% }\end{array}$ \\
\hline 3 & $238-41$ & 68 \\
\hline 4 & $257-59$ & 73 \\
\hline 5 & $183-85$ & 53 \\
\hline 6 & $191-194$ & 45 \\
\hline 7 & $123-26$ & 56 \\
\hline 8 & $113-15$ & 47 \\
\hline 9 & $85-88$ & 52 \\
\hline 10 & $76-78$ & 43 \\
\hline 11 & $153-55$ & 41 \\
\hline 12 & $184-88$ & 67 \\
\hline 13 & $112-115$ & 71 \\
\hline
\end{tabular}

Table 2: Physical data of compounds (15a -e) and (16a-e).

\begin{tabular}{|c|c|c|}
\hline $\begin{array}{c}\text { Compd. } \\
\text { No. }\end{array}$ & $\begin{array}{c}\text { M.P. } \\
\mathbf{C}^{\circ}\end{array}$ & $\begin{array}{c}\text { Yield } \\
\mathbf{\%}\end{array}$ \\
\hline $15 \mathrm{a}$ & $94-96$ & 32 \\
\hline $15 \mathrm{~b}$ & $91-93$ & 43 \\
\hline $15 \mathrm{c}$ & $154-56$ & 33 \\
\hline $15 \mathrm{~d}$ & $211-14$ & 36 \\
\hline $15 \mathrm{e}$ & $223-26$ & 47 \\
\hline $16 \mathrm{a}$ & $117-20$ & 35 \\
\hline $16 \mathrm{~b}$ & $120-22$ & 46 \\
\hline $16 \mathrm{c}$ & $149-51$ & 41 \\
\hline $16 \mathrm{~d}$ & $203-06$ & 45 \\
\hline $16 \mathrm{e}$ & $231-35$ & 52 \\
\hline
\end{tabular}

\section{RESULTS AND DISSCUSION}

During the course of our interest work towards the synthesis of new heterocyclic compounds of potential activity, acid hydrazides (1 and 2 ) are used to synthesize many acetylenic-tert-amine derivatives containing 1,3,4-thiadiazole moiety, which are well-known for their useful biological and pharmacological activities (Zuhair Muhi -Elden et al., 1985).

Acid hydrazides ( 1 and 2 ) are used for synthesis a potassium 3-substituted dithiocarbazates ( 3 and 4 ) by its reaction with carbon disulfide and potassium hydroxide in an absolute ethanol. Methylation of compounds ( 3 and 4 ) with methyl iodide under reflux afforded the corresponding methylthio derivatives (5 and 6), the I.R spectra of these 
products exhibited characteristic carbonyl bands in $1668 \mathrm{Cm}^{-1}$ and $1703 \mathrm{Cm}^{-1}$ and $\mathrm{NH}$ stretching appeared at $3196 \mathrm{Cm}^{-1}$ and $3134 \mathrm{Cm}^{-1}$.(Noori, 1999), ( Yong and Wood , 1955).

Ring closure of compounds (5 and 6) in an acidic media is well known method for the synthesis of compounds (7 and 8) (Yang et al.,1955), their I.R spectra showed absorption for $(\mathrm{C}=\mathrm{N})$ band at $1635 \mathrm{Cm}^{-1}$ and $1656 \mathrm{Cm}^{-1}$, also at $1087 \mathrm{Cm}^{-1}$ and $1095 \mathrm{Cm}^{-1}$ due to $\mathrm{C}-\mathrm{S}-\mathrm{C}$ bonds. UV spectra of compounds (7 and 8 ) showed $\lambda_{\max }(\mathrm{MeOH})$ at $268 \mathrm{~nm}$ and $260 \mathrm{~nm}$.

Oxidation of compounds (7 and 8 ) by potassium permanganate in acidic medium yielded compounds (9 and 10) respectively. The IR spectrum for these compounds disclose the presence of $\mathrm{C}=\mathrm{N}$ at $1642 \mathrm{Cm}^{-1}$ and $1658 \mathrm{Cm}-1$ and sulfonyl group at $1310 \mathrm{Cm}^{-1}$ and $1335 \mathrm{Cm}^{-1}$. The UV spectrum of these compounds have $\lambda_{\max }(\mathrm{MeOH})$ at $259 \mathrm{~nm}$ and 248 nm.

Hydrolysis of compounds (9 and 10 ) with (15\%) aqueous solution of sodium hydroxide converted them to 5-alkyl-1,3,4-thiadiazoline-2-(3H)-one (11 and 12). The IR spectra of these compounds were consistent with the presence of $(\mathrm{C}=\mathrm{N})$ at $1635 \mathrm{Cm}^{-1}$ and $1643 \mathrm{Cm}^{-1}, \mathrm{NH}$ group at $3050 \mathrm{Cm}^{-1}$ and $3064 \mathrm{Cm}^{-1}, \mathrm{C}=\mathrm{O}$ group at $1635 \mathrm{Cm}^{-1}$ and 1690 $\mathrm{NH}$ group at $3050 \mathrm{Cm}^{-1}$ and $3064 \mathrm{Cm}^{-1}$. Although compounds (11 and 12) may exist in two tautomeric forms, keto and enole, we observed that keto form was predominated since the IR spectra showed no absorption band at 3400-3500 $\mathrm{Cm}^{-1}$ related the enole form. The UV spectrum of these compounds have $\lambda_{\max }(\mathrm{MeOH})$ at $267 \mathrm{~nm}$ and $259 \mathrm{~nm}$.

The reaction of 5-alkyl-1,3,4-thiadiazole-2-(3H)-ones (11 and 12) with alcoholic sodium hydroxide followed by the addition of propagyl bromide obtained 5-alkyl-3alkylnyl-1,3,4-thiadiazole-2(3H)-ones(13 and 14), the IR spectra of these compounds are characterized by the present of $(\equiv \mathrm{CH})$ at $\left(3266 \mathrm{Cm}^{-1}\right.$ and $\left.3275 \mathrm{Cm}^{-1}\right), \mathrm{C}=\mathrm{O}$ at $\left(1735 \mathrm{Cm}^{-1}\right.$, $\left.1722 \mathrm{Cm}^{-1}\right)$ and $(\mathrm{CH}$ for $\mathrm{ArH})$ at $\left(3026 \mathrm{Cm}^{-1}\right.$ and $\left.3018 \mathrm{Cm}^{-1}\right)$ bands. While, the UV spectrum of these compounds have $\lambda_{\max }(\mathrm{MeOH})$ at $254 \mathrm{~nm}$ and $258 \mathrm{~nm}$.

The Mannich reaction of 5-alkyl-3-alkyl-1,3,4-thiadiazoline-2-(3H)-one (13 and 14) with paraformaldehyde and the appropriate amines in the presence of catalytic amount of cuprous chloride afforded the 5-alkyl-3-(4-tert-amino-2-butynyl)-1,3,4-thiadiazole-2-(3H)ones (15a-e and 16 a-e ). The structure of these products was deduced according the I.R and UV spectra which are in agreement to the published data in the same acetylenic compounds (Parikh, 1974) Table (3). 


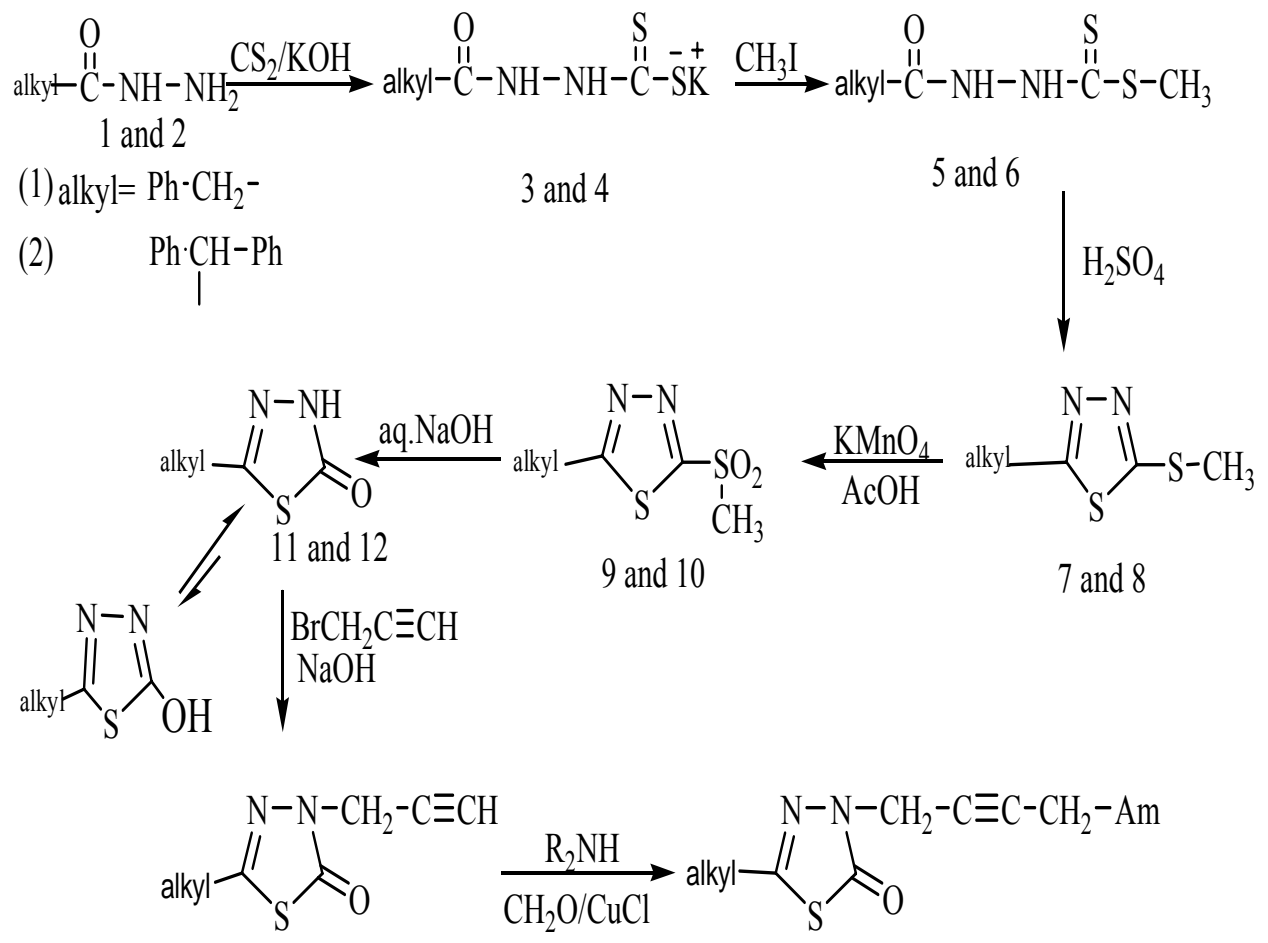

13 and 14

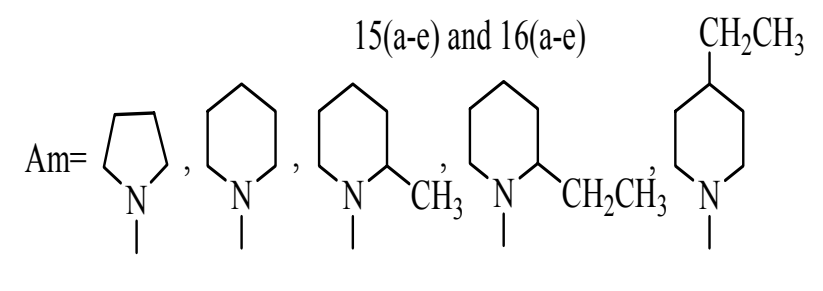
(a)
(b)
(c)
(d)
(e)

(Scheme 1) 
Synthesis of some Derivatives 2-Aryl $-1,3,4-\ldots \ldots$.

Table 3: Spectral data of compounds (15 a-e ) and (16 a-e ).

\begin{tabular}{|c|c|c|c|c|c|c|c|}
\hline \multirow{2}{*}{$\begin{array}{c}\text { Comp. } \\
\text { No. }\end{array}$} & \multirow{2}{*}{ Am } & \multicolumn{5}{|c|}{$\mathbf{I R}(\mathrm{kBr}) \gamma, \mathrm{Cm}^{-1}$} & \multirow{2}{*}{$\begin{array}{c}\mathrm{UV}, \lambda_{\max } \\
(\mathrm{nm}) \\
(\mathrm{MeOH})\end{array}$} \\
\hline & & $\mathbf{C}=\mathbf{O}$ & $\mathbf{C}=\mathbf{N}$ & $\mathrm{C} \equiv \mathrm{C}$ & C-S-C & CH-Ar & \\
\hline $15 \mathrm{a}$ & & 1713 & 1592 & $2105\left(\mathrm{Vw}^{*}\right)$ & 1035 & 3053 & 268 \\
\hline $15 b$ & & 1708 & 1588 & 2098(vw) & 1079 & 3042 & 255 \\
\hline $15 \mathrm{c}$ & & 1718 & 1610 & 2118(vw) & 1068 & 3050 & 243 \\
\hline $15 d$ & & 1722 & 1612 & 2122(vw) & 1072 & 3033 & 239 \\
\hline $15 \mathrm{e}$ & & 1707 & 1623 & $2100(\mathrm{vw})$ & 1090 & 3047 & 244 \\
\hline $16 \mathrm{a}$ & & 1705 & 1604 & 2090(vw) & 1075 & 3055 & 259 \\
\hline $16 b$ & & 1700 & 1595 & 2113(vw) & 1083 & 3028 & 248 \\
\hline $16 \mathrm{c}$ & & 1709 & 1598 & $2105(\mathrm{vw})$ & 1072 & 3031 & 241 \\
\hline $16 \mathrm{~d}$ & & 1710 & 1623 & 2108(vw) & 1083 & 3041 & 253 \\
\hline $16 \mathrm{e}$ & & 1698 & 1611 & $2117(\mathrm{vw})$ & 1094 & 3052 & 264 \\
\hline
\end{tabular}

$\star$ ॠw (very weak ) 


\section{REFERNCES}

AL-Ajely, M.S.; Basher, H.A.; Hussein, Y. (2003). Synthesis of some aminobutyl N -[tetra (or eghorohex) hydrophthalogl] amino acidester . J. Edu. and Sci., 15, 18.

Almasirad, A.; Vousooghi, N.; Tabtabai , S.A. ; Kebriaeezadeh , A. ; Shafiee, A.(2007) Synthesis anticonvulsant and muscle relaxant activities of substituted 1,3,4oxadiazole,1,3,4-thiadiazole and 1,2,4-triazole. Acta Chem. Slov. 54, 317-342 .

Aly, A. A.; El-Sayed, (2006). Synthesis and biological activity of new 1,3,4-thiadiazole derivatives, Chem. Pap., 60(1), 56-60.

Chen, H.S.; Li, Z. M.; Han, Y. F.; Wang, Z.W. (1999). New fungicidal activepyrazolyl substituted 1,3,4-thiadiazole compounds and their preparation, Chinese Chem. letters , 10 (5), 365-366.

Clay, R. ; Bungay, C. (1965). "Dictionary of Organic Compounds", 4th edn., Eyre and Spottisuuoode publisher, London, 4, 1666.

Dabholkar, V.V.; Ansari, F.Y. (2008). Synthesis and biological studies of bis (thiadiazole/ triazole) by sonication . Acta Poloniac pharmaceutical Drug research, 65 (5), 521526.

Dahlbom, R. ; Mollberg, R. (1963). Aceylenic compounds of potential. Pharmacological value. 7, 916 .

El-Khwass , S.M.; Habib, N.S. (1989). Synthesis of 1,2,4-triazole [3,4- b] [1,3,4] thiadiazine derivatives of benzotriazole. J. Heterocyclic Chem., 26, 77.

Hoggarth, E. (1952). 2-Benzolydithiocarbazineic acid and related compounds. J. Chem. Soc., 4811.

Ludwig, N.; Kurt, R. ; Enst, P. (1973). Fungicidal and new atocidal 2-(4- pyridyl) -1,3,4thiadiazole derivatives. Chem. Abstract .78, 43486r.

Mohammad, H.N.; Asadipour , A. ; Letafat , B. ; Vosooghi, M.; Shadiee, A. (2009 ). vitro anti-helicobacter pyloric activity of 2-(substituted benzylthio) -5-(nitro-2furyl)1,3,4-thiadiazole derivatives . Turk. J. Chem., 33, 471-478.

Morvet, C. S. ; Mcelvian, S.M. (1941). o-chloro toluene and p-chloro toluene. Org. Synthesis coll. $1,170$.

Noori, M. S. (1999). Synthetic studies of some new polyfunctional substituted five and six membered heterocyclic compounds, Ph.D. thesis, University of Mosul, Iraq .

Parikh, V.M. (1974). "Absorption Spectroscopy of Organic Chemical Molecules". Addition-Wasley publishing company , London, $325 \mathrm{p}$.

Siddigui, N.; Rana, A. ; Khan, S. A.; Haque, S.E. ; Arshad, M.F. ; Ahmed, S. ; Ahcan, W. W. (2009). Synthesis and preliminary screening benzothiazol-2-yl thiadiazole derivatives for anticonvulsant activity. Acta Pharm, 59, 441-451.

Singh, A.C.; Langer , T.C. (1989). Synthesis of some nitro substituted 1,3,4oxadiazzoles,1,3,4-thiadiazoles and 1,2,4-triazoles as antiamebic agents. J. Indian Chem.Soc.,66(2), 122.

Vosooghi, M.; Akbrzadeh,T. ; Fallah, A.; Fazeli , M.R. ; Jamalifar, H. ; Shafie, A. (2005). Synthesis of substituted 1,3,4-oxadiazole,1,3,4-thiadiazole and1,2,4-triazole derivatives as potential antimicrobial agents. J. Sci. Islamic Rep. Iran. 16(2), 145151.

Yong, R.W.; Wood, K.H.(1955). The cyclization of 3-acyldithiocarbazate. J. Am. Chem. Soc., 77, 400 . 
Zuhair, M.; Gantous, H.; Garabet, M. (1981). Biological evaluation of N,Nbis- (4-t-amino-2-butynyl) phthalamines. Iraqi J. Sci., 22,155.

Zuhair, M.; Shams, E.; Fuad, A.; Abdul fairs, H.; Dawser, K. ; Inam S. (1985). Synthesis and biological evaluation of 5-alkyl-3-(4-tert- amino-2-butyuyl)1,3,4-thiadiazol-2(3H)-ones. Eur. J. Med , Chem. Ther. 20 (1), 33 -36. 